\title{
Synthesis and Alkali Metal Picrate Extraction Capabilities of Novel Bis(benzocrown Ethers) Based on Diphenylglycoluril
}

\author{
Alexander Yu. Lyapunov, Victor N. Pastushok, Tatyana I. Kirichenko, \\ Catherine Yu. Kulygina, Leonid S. Kikot', Tatyana Yu. Bogaschenko, \\ and Nikolay G. Luk'yanenko ${ }^{@}$ \\ A.V. Bogatsky Physico-Chemical Institute, National Academy of Sciences of Ukraine, Odessa, 65080, Ukraine \\ @Corresponding author E-mail: ngl@farlep.net
}

\begin{abstract}
Novel glycoluril-bridged bis(benzocrown ethers) have been synthesized. The appropriate bis(benzo-18-crown-6) was formed in a good yield by reaction of bis(cyclomethoxymethylene)diphenylglycoluril with benzo-18-crown-6 in polyphosphoric acid. The reaction with dibenzo-18-crown-6 under the same conditions leads only to polymeric products. The corresponding bis(dibenzo-18-crown-6) was prepared in moderate yield by the reaction of tetrakis(chloromethyl)diphenylglycoluril with the dibenzo-18-crown-6 in the presence of $\mathrm{SnCl}_{4}$ in dichloroethane. Extraction of alkali metal picrates from water into chloroform by bis(benzocrown ethers) was examined to estimate their complexation ability. The extraction capability of bis(benzocrown ethers) is much greater than of the corresponding monomeric crown ethers.
\end{abstract}

Keywords: Benzocrown ethers, dibenzocrown ethers, bis(benzocrown ethers), diphenylglycoluril, extraction.

\section{Синтез и экстракционная способность по отношению к пикратам щелочных металлов новых бис(бензокраун-эфиров) на основе Аифенилгликольурила}

\author{
А. Ю. Аяпунов, В. Н. Пастушок, Т. И. Кириченко, Е. Ю. Кулыгина, А. С. Кикоть, \\ Т. Ю. Богащенко и Н. Г. Лукьяненко@ \\ Физико-химический институт имени А.В. Богатского Национальной академии наук Украины, Одесса, 65080, \\ Украина \\ ${ }^{\circledR}$ E-mail:ngl@farlep.net
}

\begin{abstract}
Получен новый тип бис(бензокраун-эфиров), в которых два бензокраун-эфира соединены фрагментом дифенилгликольурила. Бис(бензо-18-краун-6) образуется с хорошим выходом при реакции бис(ичиклметоксиметилен)дифенилгликольурила с бензо-18-краун-6 в полифосфорной кислоте (ПФК). Взаимодействие его с дибензо-18-краун-6 в этих же условиях приводит исключительно к полимерным продуктам. Реакция тетракис(хлорметил)дифенилгликольурила с дибензо-18-краун-6 в присутствии $\mathrm{SnCl}_{4}$ в дихлорэтане приводит к образованию соответствующего бис(дибензо-18-краун-6). Изучена экстракция катионов щелочных металлов полученными соединениями из водной фазы в хлороформ. В сравнении с бензо-18-краун-6 и дибензо18-краун-6 степень экстракции пикратов щелочных металлов полученными бис(бензокраун-эфирами) значительно выше.
\end{abstract}

Ключевые слова: Бензокраун-эфиры, дибензокраун-эфиры, бис(краун-эфиры), дифенигликольурил, экстракция.

\section{Введение}

Развитие супрамолекулярной химии неразрывно связано с конструированием и синтезом новых моле- кулярных рецепторов, способных осуществлять селективное распознавание ионов и молекул. ${ }^{[1-3]}$ В ряду синтетических макроциклических рецепторов для ионов металлов и органических молекул одно из центральных 
мест занимают краун-эфиры. ${ }^{[4-6]}$ Особое внимание привлекают бис(краун-эфиры), в которых два полиэфирных цикла объединены различными мостиками. Взаимодействие отдельных краун-эфирных субъединиц таких гомо- или гетеродитопных рецепторов с субстратом может проходить независимо (статистическое комплексообразование) или с проявлением как положительных, так и отрицательных кооперативных или аллостерических эффектов. ${ }^{[7-11]}$ Положительные эффекты обычно наблюдаются при образовании сэндвичеподобных комплексов бис(краун-эфиров) с большими катионами металлов (Рисунок 1а), которые не могут поместиться в полости отдельного макроцикла или при взаимодействии с бифункциональными молекулами-гостями, например, с диаминами или дикарбоксилатами (Рисунок 1б). Кооперативное взаимодействие с субстратом двух смежных полиэфирных циклов, как правило, приводит к образованию более прочных комплексов производных бис(краун-эфиров) в сравнении с соответствующими моно(краун-эфирами). Отрицательные эффекты, обычно, являются следствием электростатического отталкивания катионов при включении их в полость каждого из краун-эфирных циклов (Рисунок 1в).

Комплексообразующие свойства бис(краунэфиров) существенно зависят от структурной подготовленности лиганда к образованию того или иного типа комплексов. Такая преорганизация может быть достигнута при связывании двух краун-эфиров конформационно жесткими соединительными фрагментами (линкерами), которые предопределяют их взаимное пространственное расположение. Очевидно, что образованию сэндвичеподобных комплексов должна способствовать син-ориентация отдельных краун-эфирных циклов бис(краун-эфиров). В этом отношении в качестве жесткого линкера привлекает внимание дифенилгликольурил. На основе его тетракиспроизводных получено много U-образных молекулярных рецепторов, так называемых молекулярных клипсов, в которых арильные заместители имеют синконфигурацию. ${ }^{[12-16]}$ Эти данные, а также результаты компьютерного молекулярного моделирования позволили нам предположить, что бис(бензокраун-эфиры) должны иметь конфигурацию краун-эфирных циклов благоприятную для образования устойчивых сэндвичеподобных комплексов.

В настоящем сообщении мы описываем синтез и экстракционную способность по отношению к пикратам щелочных металлов новых бис(бензо-18-краун-6) и бис(дибензо-18-краун-6), в которых краун-эфирные циклы соединены тетракис(метилен)дифенилгликольурилом.

\section{Экспериментальная часть}

Спектры ${ }^{1} \mathrm{H}$ ЯМР регистрировали в $\mathrm{CDCl}_{3}$ на прибоpe Varian VXR-300 с рабочей частотой 300 МГц. ББА-массспектры - на масс-спектрометре VG 7070EQ (Xе, 8 кВ) в матрице 3-нитробензилового спирта. УФ спектры записывали на спектрофотометре Specord M-40. Температуры плавления измерены в открытых капиллярах и не исправлены. Элементный анализ проводили на CHNS анализаторе EuroVector EA3000. Препаративную колоночную хроматографию осуществляли на силикагеле Kieselgel 60 (0,063-0,100 мм, «Merck»). Чистоту всех синтезированных веществ контролировали методом ТCX (Sorbfil УФ-254). Бензо-18-краун-6 (Б18К6),$^{[17]}$ дифенилгликольурил, ${ }^{[18]}$ диэфир $\mathbf{1},{ }^{[19]}$ и тетрахлорид $\mathbf{4}^{[20]}$ получали, как описано. Дибензо-18-краун-6 (ДБ18К6) коммерчески доступен.

\section{Синтез}

40b,40c-Дифенил-2,3,5,6,8,9,11,12,14,15,18,20,23,24,26,27, 29,30,32,33,35,36,39,40b,40c,41-гексакозагидро-1,4,7,10,13,16, 22,25,28,31,34,37-додекаокса-18a,19a,39a,40а-тетраазачикло окта-дека[1",2":"4',5']бензо[1',2':5, 6]азулено[2,1,8-іја]ииклооктадека[1',2':4,5]бензо[1,2-f]-азулен-19,40-дион, 2.

Метод A. Раствор 170 мг (0,45 ммоль) диэфира 1 и 281 мг (0,9 ммоль) Б18К6 в 30 г ПФК перемешивали при $80{ }^{\circ} \mathrm{C}$ в течение 30 минут. Прибавляли 70 мл воды и экстрагировали полученную смесь хлороформом $(5 \times 30$ мл). Объединенные хлороформные экстракты сушили безводным $\mathrm{MgSO}_{4}$ и удаляли растворитель при пониженном давлении. Остаток растворяли в 50 мл смеси $\mathrm{CHCl}_{3}-\mathrm{MeOH}(100: 1)$ и фильтровали полученный раствор через слой силикагеля ( 30 мл). После отгонки растворителя остаток перекристаллизовывали из смеси $\mathrm{MeOH}-\mathrm{CHCl}_{3}(50: 1)$. Бесцветные кристаллы, выход 328 мг (78\%), т. пл. $231,5-233{ }^{\circ} \mathrm{C}$. Найдено, \%: С 64,67, Н 6,31, N 5,88. $\mathrm{C}_{52} \mathrm{H}_{62} \mathrm{~N}_{4} \mathrm{O}_{14}$. Вычислено, \%: С 64,58, Н 6,46, N 5,79. $\mathrm{m} / z$ (ББА) $I_{\text {о }}, \%: 967[\mathrm{M}+\mathrm{H}]^{+}(100), 989[\mathrm{M}+\mathrm{Na}]^{+}(32), 1005[\mathrm{M}+\mathrm{K}]^{+}$ (8). ' $\mathrm{H}$ ЯMP $\left(\mathrm{CDCl}_{3}\right) \delta_{\mathrm{H}}$ м.д.: 3,56-3,81 (24H, м, $\left.\mathrm{CH}_{2} \mathrm{O}\right), 3,82-3,92$ $\left(8 \mathrm{H}, \mathrm{м}, \mathrm{CH}_{2} \mathrm{O}\right), 3,98-4,26\left(8 \mathrm{H}, \mathrm{м}, \mathrm{CH}_{2} \mathrm{O}\right), 4,13(4 \mathrm{H}$, д, $J=15,8$, $\left.\mathrm{CH}_{2} \mathrm{~N}\right), 4,67\left(4 \mathrm{H}\right.$, д, $\left.J=15,8, \mathrm{CH}_{2} \mathrm{~N}\right), 6,80\left(4 \mathrm{H}, \mathrm{c}, \mathrm{C}_{6} \mathrm{H}_{2}\right), 7,00-7,19$ $\left(10 \mathrm{H}, \mathrm{M}, \mathrm{C}_{6} \mathrm{H}_{5}\right)$

Метод Б. К раствору 500 мг (1,02 ммоль) свежеполученного тетрахлорида 4 и 675 мг (2,16 ммоль) Б18К6 в 20 мл сухого 1,2-дихлорэтана прибавляли 1 мл $\mathrm{SnCl}_{4}(8,5$ ммоль) и нагревали при перемешивании в атмосфере аргона 1 ч. Затем прибавляли 5 мл $6 \mathrm{H} \mathrm{HCl}$ и кипятили ещё 1 ч. Выпавший осадок отфильтровывали и растворяли в 40 мл метанола. Через раствор в течение 0,5 ч. пропускали сероводород, выпавший $\mathrm{SnS}_{2}$ отфильтровы-

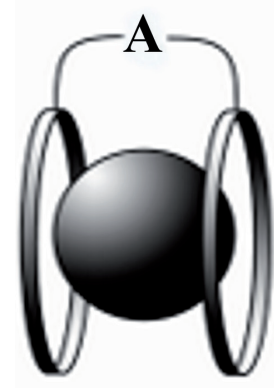

a

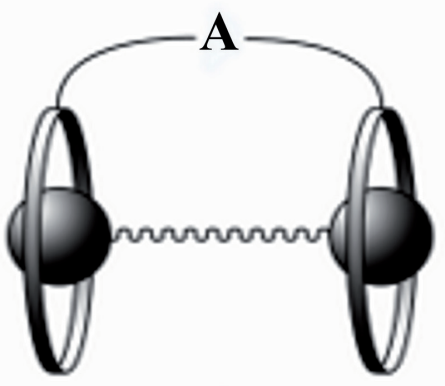

6

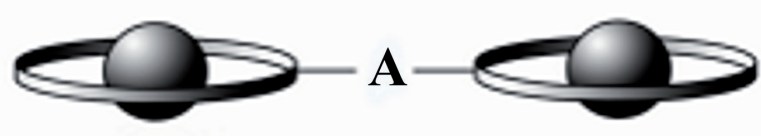

B

Рисунок 1. Схематическое представление возможных типов комплексов бис(краун-эфиров). 
вали, промывали тёплым метанолом (2×20 мл) и тёплым хлороформом $(4 \times 30$ мл). Полученный раствор промывали водой $(4 \times 40$ мл) и сушили азеотропной отгонкой воды. Растворитель удаляли при пониженном давлении, остаток перекристаллизовывали из метанола. Выход 500 мг (50\%).

37b,37c-Дифенил-6, 7,9,10,13,15,18,19,21,22,29,30,32, $33,36,37 b, 37 c, 38,41,42,44,45$-докосагидро-5, 8, 11,17,20,23, 28,31,34,40,43,46-додекаокса-13a,14a,36а,37а-тетраазабензо [10',11']ииклооктадека[1',2':4,5]бензо[1,2-f]бензо[10", $\left.11^{\prime \prime}\right]$ ииклооктадека [1", 2"::4',5']бензо [1',2':5,6]азулено [2,1,8-іjа] азулен-14,37-дион, 5 и 26b,26c-дифенил-6,9,10,12,13,18,19,21,22, 25,26b,26c-додекагидро-15,3:16,2-диметено-8,11,14,17,20,23гексаокса-4a,5a,25a,26а-тетраазаазулено[2,1,8-іjа]ииклооктадека[1',2':4,5]бензо[1,2-f]азулен-5,26-дион, 6. К раствору 500 мг (1,02 ммоль) свежеполученного тетрахлорида 4 и 756 мг (2,1 ммоль) ДБ18К6 в 50 мл сухого 1,2-дихлорэтана прибавляли 1 мл $\mathrm{SnCl}_{4}$ (8,5 ммоль) и перемешивали при комнатной температуре в атмосфере аргона 48 ч. Затем реакционную смесь кипятили 8 ч, прибавляли 5 мл $6 \mathrm{H} \mathrm{HCl}$ и кипятили ещё 1 ч. В остывшую реакционную массу прибавляли 20 мл хлороформа, органический слой отделяли, промывали $5 \%$ ным раствором $\mathrm{HCl}$, водой и сушили безводным $\mathrm{MgSO}_{4}$. После удаления растворителя в вакууме, к остатку прибавляли 20 мл ацетонитрила. Нерастворившийся осадок отфильтровывали, промывали ацетонитрилом $(4 \times 10$ мл) и использовали для выделения циклофана 6 (см. ниже). Объединенные ацетонитрильные маточники упаривали, остаток очищали колоночной хроматографией $\left(\mathrm{SiO}_{2}, \mathrm{CHCl}_{3}-\mathrm{MeOH}(25: 1)\right)$. Получали 5 в виде белого порошка. Выход 150 мг (14\%), т.пл. $235^{\circ} \mathrm{C}$ (разл.). Найдено, \%: С 67,67, Н 6,11, N 5,38. $\mathrm{C}_{60} \mathrm{H}_{62} \mathrm{~N}_{4} \mathrm{O}_{14}$. Вычислено, \%: С 67,78, Н 5,88, N 5,27. $\mathrm{m} / z$ (ББА) $I_{\text {отн }}, \%$ : 1062 $[\mathrm{M}]^{+}(100), 1085[\mathrm{M}+\mathrm{Na}]^{+}(30), 1101[\mathrm{M}+\mathrm{K}]^{+}(10) .{ }^{1} \mathrm{H}$ ЯMP $\left(\mathrm{CDCl}_{3}\right)$

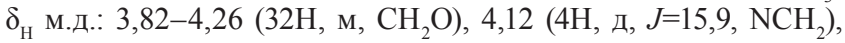
$4,66\left(4 \mathrm{H}\right.$, д, $\left.J=15,9, \mathrm{NCH}_{2}\right), 6,77\left(4 \mathrm{H}, \mathrm{c}, \mathrm{C}_{6} \mathrm{H}_{2}\right), 6,80-6,91(8 \mathrm{H}, \mathrm{M}$, $\left.\mathrm{C}_{6} \mathrm{H}_{4}\right), 7,02-7,18\left(10 \mathrm{H}, \mathrm{m}, \mathrm{C}_{6} \mathrm{H}_{5}\right)$.

Твердый остаток, полученный после фильтрования ацетонитрильного раствора, высушивали и перекристаллизовывали из толуола. Получали циклофан 6 в виде бесцветных кристаллов. Выход 40 мг (5\%), т.пл. $>350{ }^{\circ} \mathrm{C}$ (разл.). Найдено, \%: C 68,36, Н 5,45, N 7,97. $\mathrm{C}_{40} \mathrm{H}_{38} \mathrm{~N}_{4} \mathrm{O}_{8}$. Вычислено \%: С 68,48, $\mathrm{H} 5,68, \mathrm{~N} 7,75 . \mathrm{m} / \mathrm{z}$ (ББА) $I_{\text {отн. }}, \%: 703[\mathrm{M}+\mathrm{H}]^{+}(100), 725[\mathrm{M}+\mathrm{Na}]^{+}$ (6), $741[\mathrm{M}+\mathrm{K}]^{+}$(2). ${ }^{1} \mathrm{H}$ ЯMР $\left(\mathrm{CDCl}_{3}\right) \delta_{\mathrm{H}}$ м.д.: 3,54-3,71 (4H, м, $\left.\mathrm{CH}_{2} \mathrm{O}\right), 3,83-3,99\left(4 \mathrm{H}, \mathrm{м}, \mathrm{CH}_{2} \mathrm{O}\right), 4,08$ (4H, д, $J=15,3, \mathrm{NCH}_{2}$ ), $4,25-4,48\left(8 \mathrm{H}, \mathrm{м}, \mathrm{CH}_{2} \mathrm{O}\right), 4,56\left(4 \mathrm{H}\right.$, д, $\left.J=15,3, \mathrm{NCH}_{2}\right), 6.88(4 \mathrm{H}, \mathrm{c}$, $\left.\mathrm{C}_{6} \mathrm{H}_{2}\right), 7,05-7,25\left(10 \mathrm{H}, \mathrm{m}, \mathrm{C}_{6} \mathrm{H}_{5}\right)$.

\section{Экстракция пикратов щелочных металлов}

В плоскодонную колбу помещали по 2 мл $5 \cdot 10^{-3} \mathrm{M}$ водного раствора соответствующего пикрата и $1 \cdot 10^{-3} \mathrm{M}$ раствора лиганда в хлороформе, предварительно насыщенном водой, и интенсивно перемешивали на магнитной мешалке 20 мин. После центрифугирования отбирали 0,1 мл водного слоя, прибавляли к нему 5 мл дистиллированной воды и определяли концентрацию пикрата в воде после экстракции, измеряя оптическую плотность раствора при 354 нм. Степень экстракции определяли как среднее значение из трех экспериментов. Коэффициенты молярной экстинкции для каждой соли при $\lambda_{\text {макс. }} 354$ нм определены как средние значения из пяти измерений в области концентраций $10^{-2}-10^{-5}$ моль/л и составляли для пикратов: Na 14400, K 14600, Rb 15600, Cs 15400 .

\section{Молекулярное моделирование}

Поиск оптимальных структур бис(бензокраун-эфиров) 2, 5 и циклофана 6 осуществляли в два этапа. Вначале нахо- дили энергетически выгодные конформации этих соединений по методу статистической механики Monte-Carlo (силовое поле MMFF94, программный пакет Spartan'06 $\left.{ }^{[21]}\right)$. Из полученных в энергетическом окне 10 ккал/моль 100 структур каждого соединения отбирали одну - три наиболее выгодных так, чтобы их суммарная заселенность превышала 90\%. Каждую из этих конформаций затем дополнительно оптимизировали в рамках полуэмпирического метода PM3 и выбирали структуру с минимальной энергией.

\section{Обсуждение результатов}

Молекулярные клипсы на основе дифенигликольурила обычно получают при катализируемой кислотами реакции уреидоалкилирования ароматических соединений с производными тетраметилендифенилгликольурила. ${ }^{[12-16]}$ Наиболее часто для этих целей используют диэфир 1, который легко получается при конденсации дифенилгликольурила с формальдегидом с образованием тетракис(гидроксиметил)дифенилгликольурила и его последующей дегидратации. ${ }^{[19]}$ За исключением взаимодействия с гидрохиноном, уреидоалкилирование других производных бензола с участием эфира $\mathbf{1}$ осложнено длительным временем реакции и умеренными выходами продуктов. Диметиловый эфир пирокатехина и бензо-15-краун-5, очевидно и другие бензокраунэфиры, в эту реакцию вообще не вступают. ${ }^{[22]}$

Ранее нами показано, что полифосфорная кислота (ПФК) является отличным катализатором и растворителем при синтезе различных амидометильных производных бензокраун-эфиров в условиях реакции Айнхорна. ${ }^{[23]}$ При этом быстро и с хорошими выходами образуются продукты 4,5-замещения по бензольному кольцу. Поскольку диэфир 1 является классическим реагентом Айнхорна, можно было предполагать, что в указанных условиях он будет успешно взаимодействовать с бензокраун-эфирами с образованием соответствующих бис(бензокраун-эфиров).

Бис(бензо-18-краун-6) 2 образуется с выходом 78\% при нагревании в ПФК при $80{ }^{\circ} \mathrm{C}$ в течение 30 минут раствора двух эквивалентов Б18К6 и одного эквивалента диэфира 1 (Схема 1). Однако попытки получить в этих условиях бис(дибензо-18-краун-6) 5 взаимодействием ДБ18К6 с диэфиром 1 были безуспешными. Даже при больших избытках ДБ18К6 в результате реакции образуется сложная смесь веществ, предположительно продуктов поликонденсации 3.

Мы рассмотрели альтернативную возможность синтеза бис(бензокраун-эфиров) 2 и 5 взаимодействием соответствующих краун-эфиров с более реакционноспособным тетрахлоридом 4 в присутствии $\mathrm{SnCl}_{4}$, как кислоты Льюиса, в дихлорэтане. В этом случае бис(бензо-18-краун-6) 2 образуется с выходом 50\%. Учитывая необходимость дополнительных стадий синтеза тетрахлорида 4, сложность работы с ним из-за его высокой гидролитической неустойчивости и умеренный выход бис(краун-эфира) 2, проведение синтеза в ПФК представляется намного более привлекательным. В то же время в этих условиях реакция двух эквивалентов ДБ18К6 и одного эквивалента тетрахлорида 4 приводит с небольшими выходами к образованию бис(дибензо18-краун-6) 5 и, неожиданно, к циклофану 6. 

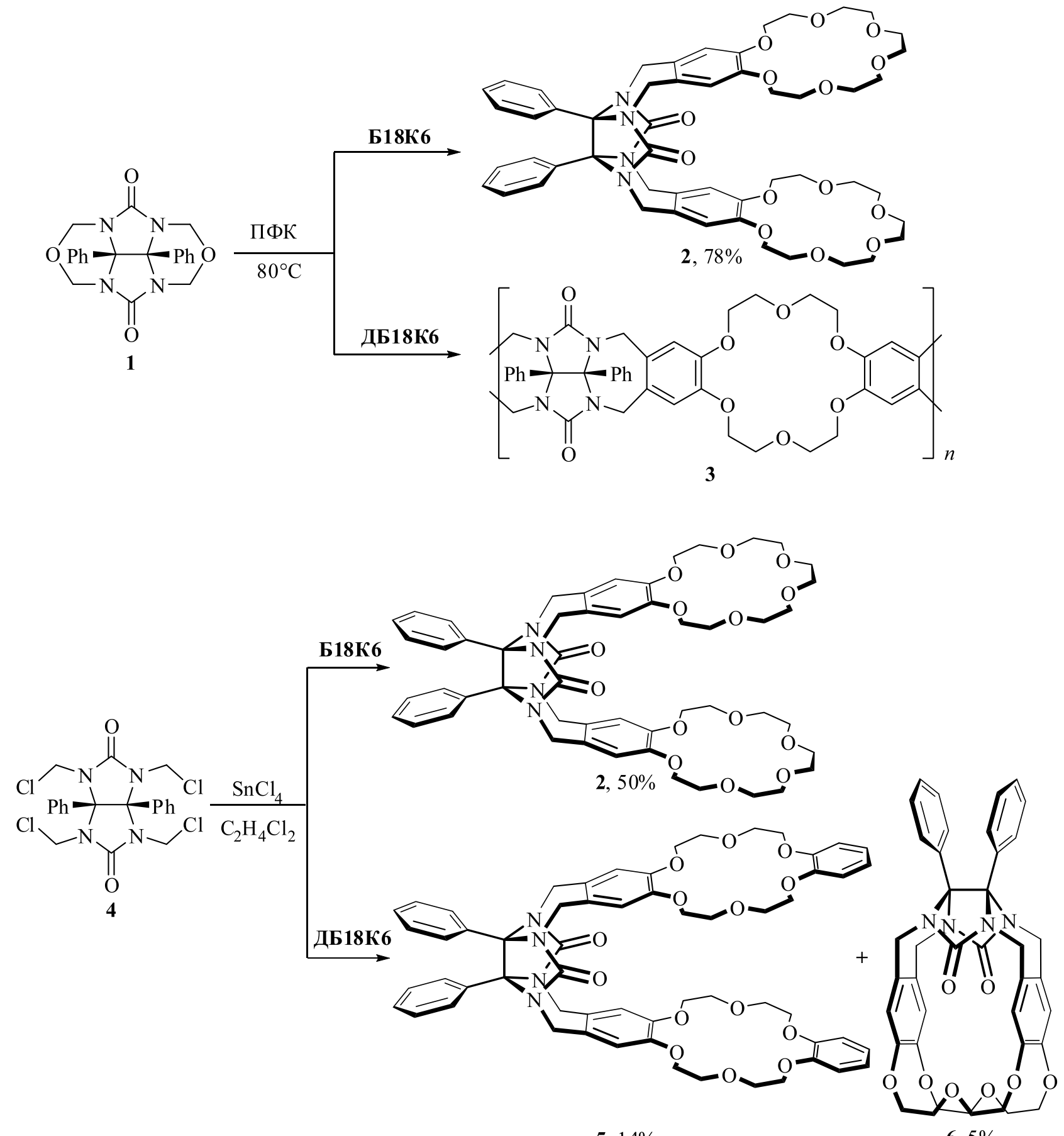

$5,14 \%$

6, $5 \%$

Схема 1. Синтез бис(бензо-18-краун-6) 2, бис(дибензо-18-краун-6) 5 и циклофана 6.

При синтезе бис(бензо-18-краун-6) 2 и бис(дибензо18-краун-6) 5 образуются только продукты с мостиковыми метиленовыми группами в 4,5 положениях бензольного кольца соответствующих бензокраун-эфиров. Это следует из анализа их ${ }^{1} \mathrm{H}$ ЯМР спектров, в которых присутствует лишь один $\mathrm{AB}$ квартет групп $\mathrm{CH}_{2} \mathrm{~N}^{1}$ и один синглетный сигнал замещенных фрагментов пирокатехина, что хорошо согласуется с $C_{2 v}$ симметрией бис(бензокраун-эфиров) $\mathbf{2}$ и 5. Отметим, что в отличие от спектра соединения 2, в спектре бис(краун-эфира) 5 наблюдается также мультиплет незамещенного фенильного кольца ДБ18К6 при $\delta=6,85$ м.д.

\footnotetext{
${ }^{1}$ Высокопольный дублет этого квартета накладывается на мультиплетный сигнал групп $\mathrm{CH}_{2} \mathrm{O}$, однако хорошо различим.
}

В отличие от спектра бис(дибензо-18-краун-6) 5 в ${ }^{1} \mathrm{H}$ ЯМР спектре циклофана 6 наблюдаются три мультиплетных сигнала неэквивалентных $\gamma, \beta$ и $\alpha$ (нумерация по отношению к бензольному кольцу) $\mathrm{CH}_{2} \mathrm{O}$ групп с центрами при $\delta=3,82,3,91$ и 4,37 м.д., соответственно. Это указывает на конформационную заторможенность, в шкале времени ЯМР, кольца краун-эфира. Присутствуют также синглетный сигнал 4,5-дизамещенных бензольных колец фрагмента ДБ18К6 при $\delta=6,88$ м.д., два хорошо разрешенных дублета мостиковых метиленовых групп при $\delta=4,08$ и 4,56 м.д. и мультиплет протонов фенильных колец дифенилгликольурила при $\delta=7,15$ м.д. Интегральное отношение интенсивностей сигналов соответствует наличию в молекуле циклофа- 
на 6 по одному фрагменту 4,4',5,5'-тетразамещенного краун-эфира и дифенилгликольурила. В сравнении со спектром бис(дибензо-18-краун-6) 5 в спектре 6 сигнал фенильных колец краун-эфира заметно смещен в слабое поле, $\Delta \delta=0,11$ м.д., что, вероятно, является следствием дезэкранирующего анизотропного влияния карбонильных групп дифенилгликольурила. Такая спектральная картина, наряду с данными масс-спектроскопии и элементного анализа, полностью соответствует приписываемой циклофану 6 структуре.

Очевидно, что устойчивость комплексов макроциклических рецепторов существенно определяется их структурной подготовленностью к акту комплексообразования. Однако нам не удалось получить монокристаллы соединений 2, 5, и 6 пригодные для рентгеноструктурного исследования. В связи с этим был осуществлен расширенный конформационный поиск их оптимальных структур по методу статистической механики Monte-Carlo (силовое поле MMFF94, программный пакет Spartan'06 $\left.{ }^{[21]}\right)$ с последующим уточнением геометрии выявленных энергетически наиболее выгодных конформаций в рамках полуэмпирического метода РМ3.

В наиболее выгодных конформациях бис(бензокраун-эфиры) $\mathbf{2}$ и $\mathbf{5}$ имеют U-образную форму с фрагментом дифенилгликольурила в основании и с краун-эфирными боковыми стенками (Рисунок 2а,б). Такая форма характерна для эффективных рецепторов ионов и нейтральных молекул, так называемых молекулярных клипсов. Образование их комплексов происходит благодаря фиксации молекулы субстрата между боковыми стенками, содержащими донорные центры. Нетрудно увидеть, что молекулы соединений 2 и 5 структурно подготовлены к образованию сэндвичеподобных комплексов со сферическими катионами металлов.

Оптимальная конформация циклофана 6 напоминает структуру криптандов. Расстояние между центроидами бензольных колец фрагмента ДБ18К6 с учетом вандерваальсовых радиусов углерода равно $1,1 \AA$, что делает невозможным, по геометрическим соображениям, включение в его внутримолекулярную полость даже маленького катиона лития (диаметр $\mathrm{Li}^{+}=1,52 \AA^{[24]}$ ). Жесткая конформация полиэфирного цикла ДБ18К6 предопределяет ориентацию неподеленных электронных пар эфирных атомов кислорода снаружи молекулярной полости (Рисунок 2в,г). Такая структура циклофана 6 допускает взаимодействие с катионами металлов только с внешней стороны фрагмента ДБ18К6. Очевидно, что устойчивость таких комплексов будет небольшой.

В химии гость-хозяин одним из наиболее распространенных способов оценки эффективности взаимодействия макроциклических рецепторов с субстратом является метод экстракции катионов в виде ионной пары с окрашенным анионом - чаще всего пикратанионом (см. например $\left.{ }^{[25-27]}\right)$. Это позволяет достаточно просто и быстро определять количество проэкстрагированного катиона спектрофотометрически. В связи с этим оценку комплексообразующей способности соединений 2, 5 и 6 проводили на основании результатов экстракции катионов щелочных металлов из водной фазы в хлороформный раствор лиганда. Для корректного сравнения в идентичных условиях определена также экстракционная способность Б18К6 и ДБ18К6. Контроль степени экстракции осуществляли на основании спектрофотометрического определения остаточной концентрации пикратов металлов в водном растворе. Экстракционную способность изучаемых соединений определяли как отношение концентрации металла к концентрации лиганда в хлороформной фазе по формуле:

Степень экстракции $(\%)=\frac{\left(\left[C_{0} M P i\right]-\left[C_{x} M P i\right]\right)_{\mathrm{H}_{2} \mathrm{O}}}{\left[C_{0} L\right]_{\mathrm{CHCl}_{3}}} \times 100$

где $\left[C_{0} M P i\right]-$ исходная концентрация пикрата металла в водной фазе, $\left[C_{x} M P i\right]-$ концентрация пикрата металла

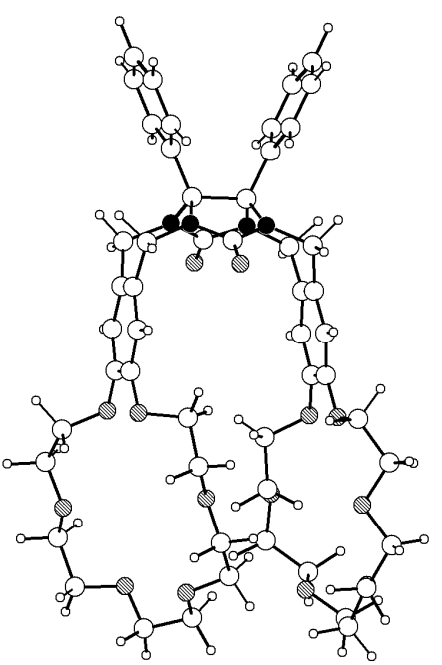

a

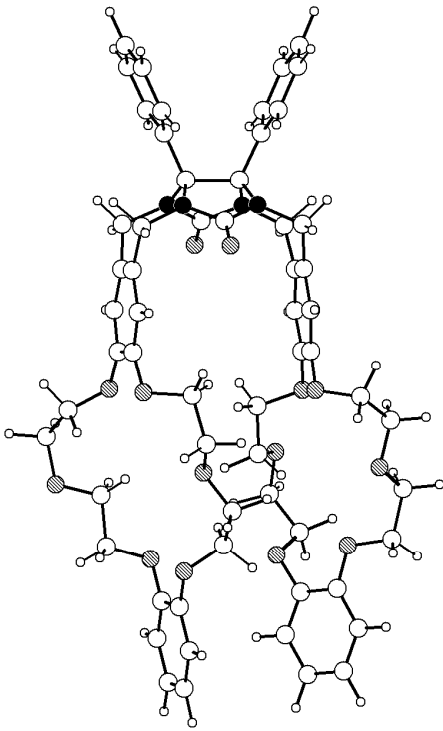

6

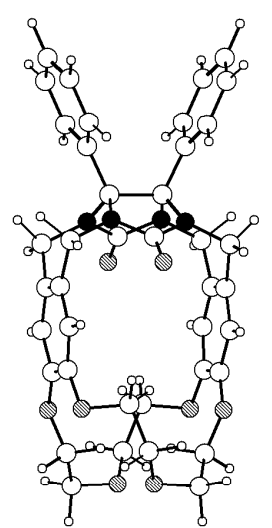

B

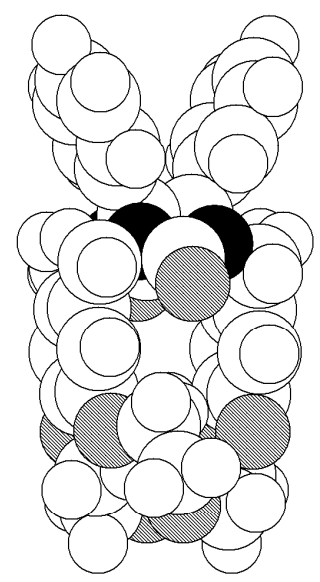

$\Gamma$

Рисунок 2. Рассчитанные структуры бис(бензо-18-краун-6) 2 (а), бис(дибензо-18-краун-6) 5 (б) и циклофана 6 (в, г). 
в водной фазе после экстракции, $\left[C_{0} L\right]-$ исходная концентрация лиганда в органической фазе.

Так как бис(краун-эфиры) 2 и 5 содержат два потенциальных места связывания катиона, то их максимальная экстракционная способность составляет 200\%, а для циклофана 6, Б18К6 и ДБ18К6 - 100\%. Полученные результаты представлены в Таблице 1 и на Рисунке 3.

Таблица 1. Степень экстракции пикратов щелочных металлов соединениями 2, 5, 6, Б18К6 и ДБ18К6, (\%)*.

\begin{tabular}{ccccc}
\hline Соединение & $\mathrm{Na}^{+}$ & $\mathrm{K}^{+}$ & $\mathrm{Rb}^{+}$ & $\mathrm{Cs}^{+}$ \\
\hline $\mathbf{2}$ & 44,2 & 142,5 & 111,6 & 107,8 \\
$\mathbf{5}$ & 13,5 & 89,8 & 63,4 & 38,3 \\
$\mathbf{6}$ & 0,5 & 1,6 & 0,3 & 0,6 \\
Б18К6 & 25,3 & 88,5 & 53,8 & 36,8 \\
ДБ18К6 & 12,9 & 71,0 & 45,4 & 31,3 \\
\hline
\end{tabular}

*Усредненные значения трех экстракционных экспериментов

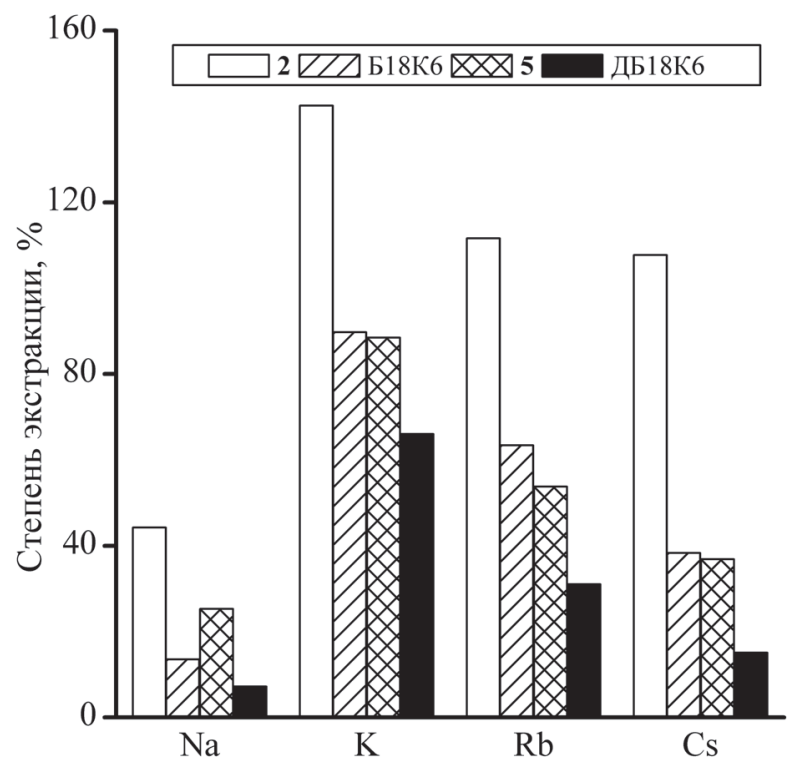

Рисунок 3. Зависимость степени экстракции пикратов щелочных металлов от типа экстрагента.

Как и предполагалось, циклофан $\mathbf{6}$ является очень слабым экстрагентом, что указывает на малую устойчивость его комплексов с катионами щелочных металлов. В сравнении с Б18К6 и ДБ18К6 степень экстракции пикратов щелочных металлов бис(бензокраун-эфирами) 2 и $\mathbf{5}$ значительно выше. Вероятно, это является следствием образования более устойчивых комплексов. Степень экстракции пикратов калия, рубидия и цезия соединением 2 превышает 100\%, что однозначно указывает на образование комплексов состава катион:лиганд 1:1 и 2:1. Образование таких комплексов в кристаллическом состоянии ранее показано нами на примере комплекса краун-эфира 2 с пикратом натрия.[28] Б18К6 и бис(бензо-18-краун-6) 2 являются более эффективными экстрагентами, чем соответствующие ДБ18К6 и бис(дибензо-18краун-6) 5. Это закономерное следствие уменьшения устойчивости комплексов при введении в полиэфирный цикл дополнительных фрагментов пирокатехина. ${ }^{[24]}$ Исследованные краун-эфиры проявляют характерный для 18-членных соединений порядок экстракционной селективности: $\mathrm{K}^{+}>\mathrm{Rb}^{+}>\mathrm{Cs}^{+}>\mathrm{Na}^{+}$, который, очевидно отражает селективность их комплексообразования с пикратами щелочных металлов.

\section{Выводы}

Предложен удобный способ получения бис(бензо18-краун-6) 2 с гликольурильным фрагментом в мостике, соединяющем два краун-эфирных цикла взаимодействием диэфира 1 с Б18К6 в ПФК. Этот способ, очевидно, может быть распространен на синтез других бис(бензокраун-эфиров). Реакция диэфира 1 с ДБ18К6 приводит только к продуктам поликонденсации. Реакция тетракис(хлорметил)гликольурила 4 с ДБ18К6 в присутствии $\mathrm{SnCl}_{4}$ в дихлорэтане приводит с небольшими выходами к образованию соответствующего бис(дибензо-18-краун-6) 5 и циклофана 6.

Изучена экстракция катионов щелочных металлов полученными соединениями из водной фазы в хлороформ. В сравнении с Б18К6 и ДБ18К6 степень экстракции пикратов щелочных металлов бис(бензокраунэфирми) 2 и 5 значительно выше. Их экстракционная селективность уменьшается в ряду: $\mathrm{K}^{+}>\mathrm{Rb}^{+}>\mathrm{Cs}^{+}>\mathrm{Na}^{+}$.

\section{Список литературы}

\section{References}

1. Lehn J.-M. Supramolecular Chemistry, Concepts and Perspectives. Weinheim: Wiley-VCH, 1995. $281 \mathrm{p}$.

2. Steed J.W., Atwood J.L. Supramolecular Chemistry, $2^{\text {nd }}$ ed. New York: Wiley, 2009. 990 p.

3. Schneider H.-J., Yatsimirsky A. Principles and Methods in Supramolecular Chemistry. Chichester: Wiley, 2000. 362 p.

4. Gokel, G. W. Crown Ethers and Cryptands. Cambridge: The Royal Society of Chemistry, 1991. 190 p.

5. Izatt R.M., Pawlak K., Bradshaw J.S. Chem. Rev. 1995, 95, 2529-2586.

6. Gokel G.W., Leevy W.M., Weber M.E. Chem. Rev. 2004, 104, 2723-2750.

7. Huang F., Zakharov L.N., Rheingold A.L., Ashraf-Khorassani M., Gibson H.W. J. Org. Chem. 2005, 70, 809-813.

8. Huang F., Gantzel P., Nagvekar D.S., Rheingold A.L., Gibson H.W. Tetrahedron Lett. 2006, 47, 7841-7844.

9. An H., Bradshaw J. S., Izatt R. M., Yan Z. Chem. Rev. 1994, 94, 939-991.

10. Rebek Jr. J., Costello T., Marshall L., Wattley R., Gadwood R. C., Onan K. J. Am. Chem. Soc. 1985, 107, 7481-7487.

11. Shinkai S., Ikeda M., Sugasaki A., Takeuchi M. Acc. Chem. Res. 2001, 34, 494-503.

12. Rowan A.E., Elemans J.A.A.W., Nolte R.J.M. Acc. Chem. Res. 1999, 32, 995-1006.

13. Wang Z.-G., Zhou B.-H., Chen Y.-F., Yin G.-D., Li Y.-T., Wu A.-X., Isaacs L. J. Org. Chem. 2006, 71, 4502-4508.

14. Chiang P.-T, Cheng P.-N., Lin C.-F., Liu Y.-H., Lai C.-C., Peng S.-M, Chiu S.-H. Chem. Eur. J. 2006, 12, 865-876.

15. Polavarapu P., Melander H., Langer V., Gogoll A., Grennberg H. New J. Chem. 2008, 32, 643-651.

16. Reek J.N.H., Elemans J.A.A.W., de Gelder R., Beurskens P.T., Rowan A.E., Nolte R.J.M. Tetrahedron 2003, 59, 175-185. 
Novel Bis(benzocrown Ethers) Based on Diphenylglycoluril

17. Bogaschenko T., Basok S., Kulygina C., Lyapunov A., Lukyanenko N. Synthesis 2002, 2266-2270.

18. Hof F., Palmer L.C., Rebek Jr. J. J. Chem. Ed. 2001, 78, 15191521.

19. Niele F.G.M., Nolte R.J.M. J. Am. Chem. Soc. 1988, 110, 172177.

20. Sijbesma R.P., Nolte R.J.M. Rec. Trav. Chem. Pays-Bas. 1993, 112, 643-647.

21. Spartan'06, Wavefunction, Inc. Irvine, CA.

22. Liu Q.-S., Gong S.-L., Ding Y., Chen Y.-Y., Wu X.-J. Synlett 2004, 2385-2387.

23. Lukyanenko N.G., Pastushok V.N., Tonya L.E., Kostyanovsky R.G. Khim. Geterotsikl. Soedin. 1987, 1039-1042. (in Russ.).
24. Izatt R.M., Bradshaw J.S., Nielson S.A, Lamb J.D., Christensen J.J., Sen. D. Chem. Rev. 1985, 85, 271-339.

25. Hausner S.H., Striley C.A.F., Krause-Bauer J.A., Zimmer H. J. Org. Chem. 2005, 70, 5804-5817.

26. Nakamura M., Yokono H., Tomita K., Ouchi M., Miki M., Dohno R. J. Org. Chem. 2002, 67, 3533-3536.

27. Casnati A., Barboso S., Rouquette H., Schwing-Weill M.-J., Arnaud-Neu F., Dozol J.-F., Ungaro R. J. Am. Chem. Soc. 2001, 123, 12182-12190.

28. Luk'yanenko N.G., Pastushok V.N., Botoshanskii M.M., Fonar' M.S., Simonov Yu.A. Zh. Neorg. Khim. 2006, 51, $2018-$ 2025 (in Russ.) [Russ. J. Inorg. Chem. 2006, 51, 1900-1907 (Engl.)]. 